\title{
Redes de Pesquisadores da Área de Administração: um Estudo Exploratório
}

\author{
Sergio Bulgacov \\ Fabiane Cortez Verdu
}

\section{ResUMO}

A proposta desta pesquisa é identificar as relações em rede que existem entre os pesquisadores que participaram do Encontro Anual da ANPAD de 1999. Os objetivos específicos são: identificar parâmetros atuais de uso de redes como instrumento facilitador e promotor de pesquisa e avaliar caminhos para a formação de grupos informais de pesquisadores. O trabalho pode ser classificado como pesquisa exploratória. O instrumento de coleta de dados foi um questionário enviado via correio eletrônico para levantar a percepção dos pesquisadores, nos meses de janeiro e fevereiro de 2000. Foram obtidas 74 respostas, correspondendo a $27 \%$ da população. Os dados apontam para as seguintes considerações, entre outras: há pouca participação dos pesquisadores em redes, apesar do uso sistemático da Internet como instrumento de trabalho; os principais restringentes foram identificados como culturais e comportamentais; as redes que existem propiciam resultados importantes; são geralmente pequenas e as relações são principalmente profissionais e sociais; a participação nas redes internacionais tem sido instrumento de aprendizagem sobre comportamento, método e conteúdo das pesquisas.

Palavras-chaves: redes de pesquisa; pesquisadores; Internet.

\begin{abstract}
The aim of this work is to identify the existing relations in network among researchers that have participated in the ENANPAD of 1999. The specific purpose is to identify network parameters used as instruments of research productivity, and to evaluate these parameters for the formation of informal researchers groups. This paper may be classified as an exploratory research. The instrument was a questionnaire sent by e-mail in order to get the perception of the researchers in January and February 1999. A total of 74 answers obtained represented $27 \%$ of the foreseen population. The data point out the following consideration, among others: there is little participation in research network, despite the common and systematic use of internet as a working instrument; the main restrictions were identified as cultural and behavioral. The network relations perform important results in research productivity. The networks are small and the relations are mainly professional and social, and the participation has been identified as an important instrument of learning about research behavior, method and content.
\end{abstract}

Key words: research network; researcher; Internet. 


\section{INTRODUÇÃO}

Em recente encontro de pesquisadores do Grupo de Estudos da Área de Organizações (GEO), presentes no XXIII Encontro Anual da Associação Nacional dos Programas de Pós-Graduação em Administração (ENANPAD), extenso debate sobre o conteúdo dos trabalhos de pesquisa da área foi desenvolvido, com a participação dos Professores Antonio Virgílio Bittencourt Bastos, Clóvis L. Machado-da-Silva, Sergio Bulgacov, Suzana Braga Rodrigues e Tânia Fischer. Bastos apresentou uma análise de artigos nacionais de administração publicados, especificando que os dados expõem a superficialidade das pesquisas e que esses apenas reproduzem o conhecimento já existente em outros países, não passando de meras ilustrações e raramente podem ser efetivamente aplicados. Segundo o autor, os trabalhos têm agregado pouco à evolução do campo no Brasil. As metodologias geralmente utilizam descrições com tratamento insuficiente dos dados para validar os resultados.

De modo geral, os demais apresentadores desse encontro concordaram que o número de pesquisadores da área é pequeno, com produção insuficiente e os trabalhos são desenvolvidos de forma fragmentada e descontínua. O grupo propôs que sejam identificadas formas de produção científica que visem à ampliação da qualidade das pesquisas e à redução da pouca seriedade coletiva, mediante contato permanente entre os participantes individuais e os grupos de pesquisas. O modelo de organização, ainda em fase de estudo, deve facilitar estas conquistas: a identificação das áreas e subáreas de interesse dos pesquisadores; o contato e a troca permanente entre os pesquisadores. Uma das alternativas lembradas foi a organização em redes informais; tal modelo pode agregar pesquisadores e facilitar a troca de conhecimentos, a crítica compartilhada, com maior aprofundamento no conteúdo, e a aplicação dos trabalhos.

A partir dessas considerações, pretende-se com este trabalho identificar as relações em rede que existem entre os pesquisadores que participaram do último ENANPAD em 1999. Os objetivos específicos são estes: identificar parâmetros atuais de uso de redes, como instrumento facilitador e promotor de pesquisa; e avaliar caminhos para a formação de grupos informais de pesquisadores. A seguir, com base na literatura, delineiam-se os principais fundamentos conceituais. 


\section{Fundamentos Téórico-Empíricos}

Muitas instituições desenvolveram, através do tempo, uma nova lógica organizacional, baseada na busca e formação do conhecimento pela pesquisa. Sua aplicação em áreas de criação e formação do conhecimento, assim como o trabalho desenvolvido por pesquisadores e professores das universidades permitem inúmeros avanços, se ocorrer a inovação e a competência na busca de soluções para os problemas existentes. Contemporaneamente, as condições ambientais dinâmicas e a complexidade dos problemas existentes determinam que as habilidades envolvidas requeiram a identificação de novas oportunidades de conhecimento por meio da participação em sem número de relacionamentos interpessoais e interinstitucionais, que venham a facilitar a difusão do conhecimento, a aprendizagem e o desenvolvimento tecnológico.

A análise interorganizacional tem propiciado diferentes perspectivas como estas: dependência de recursos, redes, ecologia populacional e institucionalismo. O conjunto dessas condições pode causar receios aos analistas, pois significa que não atuam com apenas uma única situação, mas com várias fora de seu controle individual. Ao atuar com redes de relacionamento, trabalham com um conjunto de participantes independentes, que é algo muito desafiador e complexo (Daft, 1999).

Não poucos profissionais e pesquisadores sempre trabalharam de forma independente, com atuação individual ou em pequenos grupos locais; entretanto, para o autor, está ocorrendo um realinhamento nos relacionamentos. A perspectiva da rede cooperativa é uma alternativa que surgiu para além da teoria da dependência de recursos. As ações individuais se juntam para se tornarem mais competitivas e compartilharem recursos escassos. Um exemplo mais amplo dessas iniciativas recentes é o desenvolvimento das universidades corporativas, dentro das grandes empresas. Existem mais de 1.000 universidades corporativas nos Estados Unidos, em comparação com as 200 que existiam há poucos anos. Um dos motivos pelos quais elas se desenvolveram tão rapidamente foi a impossibilidade de atendimento das empresas pelas universidades, que são muito apegadas a idéias e maneiras de ensinar tradicionais.

Segundo a literatura, as relações interinstitucionais cooperativas ou redes de relacionamento visam principalmente ao aproveitamento das oportunidades existentes no desenvolvimento das áreas de atuação. Visam também ao enfrentamento das ameaças e do acirramento das dificuldades ambientais. Essas relações interinstitucionais cooperativas, que procuram facilitar o atingimento do objetivo comum, garantindo a autonomia e independência de cada participante, 
é denominada rede organizacional. As redes selecionam parceiros preferenciais com ações complementares em áreas de ação conjunta. Procuram propiciar, em alguns casos, avanços tecnológicos, acesso a informações e ampliação da capacidade de negociação e obtenção de recursos (Freeman, 1991; Nohria, 1992; Nadler, Gerstein e Shaw, 1994; Powell, 1995; Castells, 1996). Para Daft (1999) as organizações podem escolher e construir relacionamentos de maneiras diferentes: indicar parceiros preferenciais, estabelecer acordos, compartilhar projetos e informações ou mesmo realizar atividades em conjunto.

Independentemente dos motivos que norteiam a formação da rede e a colaboração, seja que se vise à aquisição de novos conhecimentos ou mesmo à busca de maior envolvimento com determinada comunidade profissional, o relacionamento em rede é uma nova lógica organizacional. Na visão adaptada de Powell (1998), esta concepção de organização, juntamente com a visão da rede como veículo de produção, síntese e distribuição de idéias, tem permitido, cada vez mais, o sucesso dos projetos de investigação, por estarem cada vez mais ligados às relações com diferentes indivíduos e comunidades, nos quais a capacidade interna e a colaboração externa são complementares.

Cooperação, para muitos autores, é o termo chave para o funcionamento adequado da rede. Todos os seus participantes devem perceber vantagens e assimetria relativa nos ganhos dos membros para a sua manutenção. As redes podem ser vistas como estrutura de pessoas (Amorim, 1999). As conexões entre as pessoas, grupos informais ou organizações, podem ser estudadas por meio de sua forma ou conteúdo. A forma é a medida da intensidade das relações e o nível de envolvimento entre os participantes. A intensidade entre os participantes pode ser medida pelas relações e pelos documentos e relatórios produzidos, tais como artigos publicados. A força da intensidade pode ser analisada pela duração da relação, da intensidade emocional, da confiança mútua e da reciprocidade que estabelece o vínculo. $\mathrm{O}$ conteúdo é o tipo de relações que a forma apresenta. $\mathrm{O}$ conteúdo da rede pode ser social, econômico, de amizade e parentesco, ou de status e político, entre outros.

Sintetizando as diferentes posições dos autores citados, a cooperação nas ações de pesquisa podem conduzir ao compartilhamento de recursos e informações, ao estabelecerem novas áreas de investigação, no uso de programas e metodologias e redução de tempo e custos. A cooperação é um pré-requisito para a inovação, solução de problemas e desempenho. Além disso, as parcerias podem representar corte nas distâncias para o ingresso nas esferas internacionais de investigação, com projetos grandes e pequenos, que estabeleçam parcerias no exterior e no país.

Já se sabe que, para haver sucesso nas participações em rede, os parceiros 
precisam adotar um conjunto de regras básicas e a elas aderir, para gerar transações valiosas e confiáveis. O sentido de parceria tem de se tornar uma realidade reforçada, em que a lógica do benefício auferido pelos participantes seja questão fundamental (Johnston e Lawrence, 1997).

Teoricamente, segundo Powell (1998), a análise das várias formas de colaboração tem dois focos principais: a identificação das transações e trocas que acontecem; e as relações e os mecanismos por meio dos quais as informações são transferidas e ocorre o ajustamento mútuo entre os participantes. Esta linha de investigação, identificada mais nas teorias sociais e da administração, adota o foco processual, procurando verificar se os padrões das atividades requerem comunicações contínuas e aprendizagem organizacional e em que extensão a colaboração está estabelecida. Esta abordagem focaliza a capacidade do relacionamento, o modelo estabelecido das relações e como e quando os participantes da rede são capazes de combinar suas competências com as habilidades dos outros participantes. Essas capacidades não são vistas como estáticas, mas emergem e se aprofundam através do tempo, à medida que os participantes desenvolvem as relações existentes e exploram novas relações.

O terceiro campo de estudos reporta-se à confiança no relacionamento e às transformações que ocorrem em todos os participantes. Powell (1998) indica que aqueles posicionados em uma rede de relações externas adotam mais inovações administrativas e o fazem mais cedo que os demais. A presença em uma rede de colaboração intensa pode alterar a percepção de concorrência dos participantes, alterando os seus próprios horizontes organizacionais.

Os instrumentos de relacionamento utilizados pelas redes de pesquisadores geralmente envolvem dois grandes grupos. Aqueles que utilizam os mais tradicionais como cartas e bibliotecas, com mecanismos já disseminados na comunidade de usuários. E outros, que utilizam a Internet, com fornecimento de mecanismos de relacionamento, em que os mais utilizados compõem este elenco: o correio eletrônico, serviço mais básico da Internet; as listas de discussão, com a formação de grupos de debate, por meio da permissão da comunicação entre usuários de diferentes computadores, que compõem grupos de debate ou grupos de interesse; e a Web ou rede de hipertexto, conectando documentos e recursos em nível mundial. Os locais de acesso são denominados páginas e podem ser acessados facilmente por qualquer computador conectado à rede telefônica (Ciria, 1997).

Ramos (1998), em análise da percepção sobre o uso da Internet por professores de pós-graduação brasileiros, identifica o reconhecimento amplo dos benefícios para os indivíduos e organizações que se valem da tecnologia da informação. O ganho potencial não é totalmente obtido, devido a fatores críticos relaci- 
onados com o processo de gerenciamento da difusão e aplicação do processo de trabalho. Os resultados da análise indicam também como fator impulsionador a facilidade com que a tecnologia tem permitido interligar pesquisadores, possibilitando a comunicação e cooperação em projetos acadêmicos e conhecer e compartilhar resultados de pesquisa. Por outro lado, aponta a pesquisadora, os dificultadores mais significativos relacionam-se ao suporte tecnológico e de recursos humanos. Recomenda ações gerenciais, na perspectiva de uma gestão eficaz da informação, orientada para o contexto acadêmico.

Johnston e Lawrence (1997) identificam outros fatores comportamentais restringentes, lembrando que o relacionamento livre entre as partes é um relacionamento reservado, se não antagônico, arraigado no medo de que a outra parte assuma um comportamento oportunista. Naturalmente, nessas condições as pessoas tendem a compartilhar o mínimo possível de informações, restringindo o uso do conhecimento que advém do outro ponto da rede. Em ambientes de rede com coordenação centralizada ou única, esta condição pode tornar-se ainda mais saliente, dificultando a execução de tarefas que requerem confiança e valores pessoais distintos.

\section{Metodologia}

Este trabalho pode ser classificado como pesquisa exploratória (Selltiz e Deutsch, 1974), à medida que procura identificar as relações em rede entre pesquisadores brasileiros da área de administração como instrumento facilitador e promotor de pesquisa. A pesquisa exploratória aqui utilizada visa a produzir uma descrição qualitativa e quantitativa do uso de redes por meio da percepção dos pesquisadores participantes do estudo, para identificar e descrever propostas para novos trabalhos de investigação.

A população envolvida pode ser considerada composta por todos os pesquisadores brasileiros que participaram em 1999 do XXIII Encontro Anual da Associação Nacional dos Programas de Pós-Graduação em Administração em Foz do Iguaçu, das áreas de Administração da Informação, Administração de Ciência e Tecnologia, Marketing, Organizações, Estratégia, Operação, Logística e Serviços e Recursos Humanos, e que tinham os seus endereços eletrônicos registrados nos anais do encontro, perfazendo um total de 275 pesquisadores.

O instrumento de levantamento de dados foi um questionário enviado via correio eletrônico para toda a população, nos meses de janeiro e fevereiro de 2000. Foram obtidas 74 respostas, correspondendo a $27 \%$ da população. Esta amostra 
pode ser considerada como não probabilística intencional. Os resultados não devem servir como generalização para a população de pesquisadores; no entanto devem permitir a descrição de alguns parâmetros do comportamento da amostra dos pesquisadores que responderam ao questionário.

\section{AnÁlise e Discussão}

A transcrição e análise dos dados, após sua depuração e comparação com as informações apresentadas na base teórica, permitiram o alcance dos objetivos propostos. As informações foram subdivididas em duas partes: o perfil dos respondentes e da instituição representada; e a segunda parte contém as informações da pesquisa em si. O levantamento, com a tabulação de todos os questionários, elaborada por meio de estatística simples, representa o tratamento das respostas obtidas, permitindo verificar o resultado de cada uma das questões.

\section{Identificação dos Respondentes}

Para a identificação dos pesquisadores e suas instituições foram feitas 6 questões. A primeira referente à atividade principal dos respondentes que corresponderam a 5 grupos distintos, conforme quadro:

\begin{tabular}{|l|r|}
\hline Professores & 46 \\
\hline Mestrandos & 12 \\
\hline Coordenadores de curso e unidades de pesquisa & 8 \\
\hline Doutorandos & 5 \\
\hline Analistas e pesquisadores & 3 \\
\hline
\end{tabular}

Aferidos pelo tempo, os pesquisadores repartem-se em 4 grupos; nota-se que a maior parte deles está apenas iniciando a atividade.

\begin{tabular}{|l|r|}
\hline De 1 a 3 anos & 29 \\
\hline De 4 a 6 anos & 18 \\
\hline De 7 a 9 anos & 11 \\
\hline Acima de 10 anos & 16 \\
\hline
\end{tabular}


A última titulação acadêmica dos respondentes compreende principalmente mestrado e graduação. Os graduados são, na sua grande maioria, mestrandos.

\begin{tabular}{|l|r|}
\hline Doutores e pós-doutores & 24 \\
\hline Mestres & 35 \\
\hline Graduados & 15 \\
\hline
\end{tabular}

O quadro das instituições representa, de certa forma, a origem das pesquisas brasileiras, ou seja, desenvolvidas principalmente em instituições públicas:

\begin{tabular}{|l|r|}
\hline Universidades públicas & 45 \\
\hline Universidades ou faculdades privadas & 17 \\
\hline Organizações estatais & 6 \\
\hline Sem vínculo & 6 \\
\hline
\end{tabular}

As instituições representadas possuem os seguintes cursos de pós-graduação:

\begin{tabular}{|l|r|}
\hline Especialização lato sensu & 50 \\
\hline Mestrado & 57 \\
\hline Doutorado & 28 \\
\hline
\end{tabular}

\section{Dados da pesquisa}

Para o levantamento dos dados da pesquisa foram feitas 8 questões. A primeira questão corresponde às percepções dos pesquisadores sobre os trabalhos brasileiros, publicados na área de administração. Sessenta e um por cento dos respondentes indicaram posições que correspondem às mesmas constatações do grupo participante do GEO em 1999, ou seja, caracterizam as pesquisas como desenvolvidas de forma fragmentada ou descontínua; 30\% dos respondentes relatam as pesquisas desenvolvidas como inovadoras ou que agregam conhecimento; e apenas $17 \%$ deles caracterizam as pesquisas como superficiais ou que apenas reproduzem os conhecimentos existentes. Além destas respostas, podemse identificar outras considerações sobre a pesquisa desenvolvida no Brasil em administração, como as seguintes. 
. "A falta de planejamento da pesquisa gera a fragmentação".

. "Alguns trazem inovações (ou fazem ressurgir idéias inovadoras) importantes, interessantes".

. "Com algumas exceções, agregam conhecimento".

. "Com desníveis grandes (boas contribuições e trabalhos simples, repetitivos)".

. "Criativas".

- "Excesso de estudos de caso, com limitadas possibilidades de generalização; uso de um número limitado de métodos de pesquisa e grande preconceito (e ignorância) com relação aos não usados; ausência de projetos de investigação a longo prazo, o que dá a impressão de que os estudos foram feitos primeiramente para atender a objetivos de consultoria, sendo depois 'aproveitados' para pesquisa".

. "Todas, de uma forma ou de outra, contribuem para geração de conhecimento".

. "Reproduzem e agregam conhecimento, mas são descontínuas".

. "Não apresentam aplicabilidade".

- "Parte dos trabalhos reproduz conhecimentos existentes e parte consegue agregar conhecimento; ainda assim, têm uma característica comum: estão presos ao formalismo do método".

- "Superficiais e desenvolvidos de forma fragmentada e/ou descontínua, de certo modo há muita reprodução".

. "Utilizam-se em excesso autores estrangeiros e teorias desenvolvidas em contexto de países de primeiro mundo. Poder-se-ia formar um corpo teórico assentado nas organizações brasileiras, subsidiárias de transnacionais ou empresas majoritariamente nacionais".

Todos os pesquisadores utilizam material impresso (artigos, dissertações, teses, livros, revistas, jornais etc.). Quanto ao material virtual, obtido por meio da Internet, $95 \%$ dos pesquisadores o utilizam (base de dados, sites, bibliotecas virtuais de outras instituições etc.).

A impossibilidade, por diferentes motivos, de acesso direto ao material desejado, leva o pesquisador a valer-se deste elenco: 44 pedem o material pelo COMUT; 52 entram em contato com colegas de outras instituições que possam ter este material; 50 vão até a biblioteca física de outras instituições. Outras opções levantadas pelos pesquisadores foram relacionadas como segue. 
. Consulta a especialistas no tema.

. Contato com a Association for Consumer Research (ACR).

. Internet (e.g., winspirs).

. Apoio da bibliotecária, que pesquisa dentro das palavras-chaves.

. Serviço de busca mantido pelo Conselho Britânico.

. Dirige-se por e-mail aos pesquisadores que os publicaram.

A grande maioria dos pesquisadores, $92 \%$ aproximadamente, responderam que utilizam a Internet como instrumento para obtenção de material de pesquisa. Dos 74 apenas 6 responderam não a utilizar. Os principais usos são os relacionamentos via e-mail ou pesquisa no hipertexto. Metade dos que se valem da rede utilizam-na para pesquisa em sites específicos de bibliotecas, universidades e técnicos. Apenas 4 respondentes utilizam sites de periódicos e journals regularmente.

A participação em redes de pesquisadores foi respondida positivamente por 30 pesquisadores, aproximadamente $40 \%$ da amostra. Os restantes 44 não participam de redes; portanto, apesar das possibilidades e recursos da tecnologia da informação, em que $92 \%$ utilizam a Internet, identificados na questão anterior, a maioria dos pesquisadores não participam de redes de pesquisadores. Este aspecto corrobora as conclusões de Ramos (1998), na análise da percepção sobre o uso da Internet por professores de pós-graduação brasileiros: identifica-se o reconhecimento amplo dos benefícios para os indivíduos e para as organizações, quando é utilizada a tecnologia da informação; ainda assim, o ganho potencial não é de todo assegurado, devido a fatores críticos relacionados com o processo gerencial da difusão e aplicação do processo de trabalho.

Ainda assim, há indícios da constatação de Daft (1999), quando relata o excessivo apego dos pesquisadores das universidades americanas a idéias e maneiras tradicionais de atuação. Da mesma forma, as observações de Johnston e Lawrence (1997) identificam outros fatores comportamentais restringentes que impedem o relacionamento mais livre exigido pelas redes de pesquisa. Nessas condições as pessoas preferem evitar o compartilhamento de informações, reduzindo a disseminação do conhecimento ao seu núcleo de atuação e poder ou margem de segurança.

Quanto aos tipos de redes ou grupos de pesquisa, 30 dos 74 respondentes relataram participar ativamente. As participações ocorrem em diferentes tipos de redes. Algumas das redes apontadas estão relacionadas como abaixo se elencam. 
. Grupo formado por alunos e professores de cursos de pós-graduação.

- Grupo formado por pesquisadores de áreas específicas: GRUDEO; CMDNETLIST (Conflict Management Division); sistemas de informações (AIS-USA); estudos de empreendedorismo; estudos de redes organizacionais, formado em 1999 no ENANPAD; novas tecnologias em gestão de recursos humanos; grupos apoiados pelo PRONEX (UnB, UFMG e UFU); estudos de psicologia social e do trabalho; estudo intedisciplinar de micro e pequena empresa; meio ambiente; novas tecnologias; psicologia social e da saúde; pesquisas em automação da UFPE; rede GINEIT e NINEIT; pesquisas com relações interinstitucionais; rede sobre o terceiro setor no Brasil e na América Latina; RELNET relações internacionais formado no ENANPAD em 1999; WORKLEARNING e-group, learning at work discussion list;

. outras: AGREN; Association of Consumer Research; Business History; CAPES/ COFECUB; CEMBAL; Ciências Sociais no Brasil; Economics Research Network; E-groups e informações sobre mercados; Inter-réseaux; Linkage; lista de discussão sobre cinema e audiovisual do Ministério da Cultura; Núcleo de Relações de Trabalho e Novas Tecnologias Gerenciais do CEPEAD/UFMG; OMT (Academy of Management - Management Division); ORGCULT; Pegasus, na área de aprendizagem organizacional; RECOPE; Rede aliança; Rede de Estudos do Terceiro Setor da PUC-PR; Sociedade de Economia Política do PPGA/UFRGS; Redes integradas ao Núcleo de Estudos sobre o Poder e Organizações Locais; SCOS; OIT e RITS ligadas ao terceiro setor e à gestão do trabalho; Western marketing educator.

O tempo de participação nas redes pelos pesquisadores que as utilizam como instrumento de pesquisa e investigação, foi separado em três grupos: menos de um ano com 3 participantes; de um a três anos com 24 participantes; e mais de três anos com 3 participantes.

As respostas estão coerentes com o período da disseminação das novas tecnologias da informação, que facilitaram o surgimento das redes de pesquisa. Alguns pesquisadores participam de redes que surgiram antes da Internet. O relacionamento entre os participantes certamente se dava por meio de outros instrumentos de comunicação e relacionamento.

As redes representadas pelos grupos de pesquisadores da área de administração geralmente são formadas por poucos pesquisadores. O número de participantes das diferentes redes citadas pode assim distribuir-se: de 2 a 20 pesquisadores (27 respondentes); de 21 a 100 pesquisadores (12 respondentes); e mais de 101 pesquisadores (5 respondentes). Identifica-se, portanto, que os grupos de relacionamento são constituídos de poucos participantes, para os quais o conhe- 
cimento do profissional e os relacionamentos sociais são percebidos como de vital importância para o sucesso da rede.

Os participantes da rede geralmente assim se apresentam: (25) pesquisadores de universidades brasileiras; (21) pesquisadores da mesma universidade ou empresa; (19) pesquisadores de universidades brasileiras e de outros países; (07) pesquisadores de empresas brasileiras; (06) pesquisadores de empresas brasileiras e de outros países. Nota-se que poucos participantes da rede são vinculados às empresas.

As formas de participação dos pesquisadores nas redes nas quais atuam, podem sintetizar-se como segue: (30) solicitam e recebem bibliografias; (23) solicitam colaboração dos participantes; (21) solicitam e fornecem bibliografias; (15) recebem bibliografias; (07) fornecem bibliografias.

Outras participações foram descritas também:

"Buscamos discutir assuntos relativos à área de organizações e possíveis papers para serem elaborados pelos participantes".

. "Desenvolvimento de seminários e artigos".

. "Discussão de projetos de pesquisa, construção coletiva e revisão de trabalho".

. "Elaboração de projetos e desenvolvimento de pesquisas".

"Leitura de artigos dos participantes da rede".

"Participação integrada para desenvolvimento e execução de projetos".

"Participo de bancas de mestrado ligadas à rede; pretendo estreitar mais esta colaboração e formalizá-la na minha universidade".

. "Participo de discussões".

"Participo de uma rede genealógica; nesta rede os pesquisadores investigam assuntos relacionados, para não duplicar esforços. Alguns pesquisadores têm acesso a fontes que outros não têm, e eles pesquisam essas fontes. Todo o mundo mantém todo o mundo informado dos progressos e achados. Realmente está servindo para propulsionar as nossas pesquisas e temos avançado muito nestes meses, mais do que se cada um estivesse pesquisando sozinho".

- "Recebo informações sobre eventos (cursos, seminários, chamadas de trabalho) e novas publicações".

. "Recebo resenhas, informes econômicos, fórum de debate, informações diversas". 
. "Troco idéias sobre pesquisa".

- "Troco informação sobre o andamento de meus trabalhos e dos trabalhos dos demais; trocamos experiência e articulamos propostas conjuntas de trabalho".

O potencial dos participantes, no que tange à participação efetiva nos grupos de relacionamento, é percebido como alto, conforme se observa em algumas das opiniões relacionadas em seguida.

- "Acredito que na rede profissional de que participo, todos têm participação tímida. A razão disso é que a rede não tem objetivo específico; os pesquisadores limitam-se ao intercâmbio de artigos. Já a rede hobby tem objetivo específico: estamos compartilhando o trabalho, cada um com seus meios e habilidades; o trabalho avança mais rapidamente".

• "Atividade ainda em início de implementação".

- "Como exemplo temos a rede ONÇA, atualmente a mais famosa do Brasil, que funciona com a USP, UNESP e UNICAMP e universidades americanas e européias, com o intuito de obter o seqüenciamento do DNA de várias espécies. Temos apoio da FAPESP e outras instituições do ramo médico e farmacêutico, na maioria multinacionais. Esta rede é multidisciplinar: trabalham biólogos, analistas de sistemas, engenheiros, administradores, especialistas em sistemas de telecomunicações e transferência de dados, dentre outros".

- "Como há interesse comum em desenvolver estudos sobre organizações, creio que existe grande potencial, pois o grupo visa a manter atividades acadêmicas e proximidade acadêmica, quando os alunos terminam suas dissertações".

- "Depende muito de como os participantes utilizam o potencial da rede ou da lista de discussão".

. "Em geral as pessoas são muito cooperativas".

. "Une as pessoas distantes".

- "Estou trocando ótimas informações com uma mestranda que trabalha com a indústria do entretenimento".

- "Grande potencial para troca de idéias, fonte de informação e discussão de temas".

. “Com a rápida disseminação de redes Internet e Intranet há grandes possibilidades".

. "Os resultados são sempre melhores, trabalhando em equipe". 
- “A comunicação virtual é incentivada e utilizada pelo coordenador francês do projeto e anualmente ou semestralmente são desenvolvidos seminários, onde todos se encontram".

Alguns fatores restritores são percebidos da seguinte maneira:

- "As atividades de ensino e burocráticas ocupam muito tempo, fazendo com que os grupos de pesquisa apresentem algumas dificuldades para um relacionamento mais intenso, além dos interesses teóricos dos membros".

. "Depende da abrangência do grupo".

. "Existem pessoas mais e outras menos integradas".

. "São iniciativas recentes que precisam de tempo para avaliação mais precisa".

- "Vejo muita dificuldade na conciliação de agendas e interesses, o que cria uma lacuna entre o potencial teórico do grupo e a sua efetiva utilização".

. "Faltam interesses específicos em torno de um projeto comum".

. "Não existe comunicação efetiva. Observam-se mais informações".

. "Falta de congruência de interesses de pesquisa".

Em termos de freqüência, a participação nas relações do grupo por parte dos pesquisadores respondentes apresenta-se da seguinte maneira: (15) intensamente; (10) eventualmente; (05) raramente.

A reciprocidade percebida, e que caracteriza o vínculo das redes em que mais atuam os respondentes, foi caracterizada deste modo: (8) alta (a maioria responde às necessidades da rede); (12) média (cerca de metade dos participantes responde às demandas da rede); (09) baixa (poucos respondem às demandas da rede); (01) não existe reciprocidade.

As relações entre os participantes foram identificadas como principalmente profissionais por todos os respondentes e de amizade pela maioria deles (90\%). $\mathrm{O}$ vínculo informal obteve alto grau de adesão, obtendo 21 respostas, que representam $70 \%$ dos respondentes. Outras categorias compuseram esta distribuição: sociais, $50 \%$; políticas, $30 \%$; e econômicas, $17 \%$.

As redes constituídas, na percepção dos participantes, são formadas preponderantemente por vínculos profissionais, de amizade e sociais. O lado econômico representa pequena participação, tendo em vista a pequena inserção das pesquisas universitárias brasileiras da área de administração em instituições e empresas de interesse econômico. 
A participação nos grupos de pesquisa já permitiu, segundo os dados levantados, a publicação de artigos em parceria com membros da rede em 21 casos, ou seja, 70\% dos participantes de redes já escreveram artigos em parceria. Isso tende a corroborar o que Powell (1998), Ramos (1998) e Daft (1999) relatam sobre os motivos da formação da rede e da colaboração, ou seja, adquirir novos conhecimentos ou buscar maior envolvimento com a comunidade profissional para o alcance de maiores resultados nos projetos de investigação. Os resultados são ampliados por estarem cada vez mais ligados às relações com diferentes pesquisadores, onde a própria capacidade e a colaboração de outros participantes são somadas.

Outros hábitos de pesquisa que os pesquisadores possuem e que se referem à colaboração e reciprocidade na elaboração de trabalhos, foram assim arrolados.

. "Na elaboração de trabalhos, com realização de pesquisa entre os diferentes grupos".

. "Recebimento via e-mail de newletters por meio de cadastro nos sites".

"Troca de informações entre os participantes de diferentes áreas de interesse, em que o conhecimento dos participantes e suas áreas de investigação é fundamental".

. "Conversas ou colóquios virtuais com hora, data e local (site) predeterminados".

- "Troca constante de informações por meio da internet (e-mail e FTP), com resultados específicos, assim como a publicação de livro em rede. A espinha dorsal desse movimento é um pesquisador francês que, pela muita insistência, consegue a participação de outros".

- "Apresentação de painéis de pesquisa em que os participantes que 'assistem' à idéia fornecem sugestões de melhoria, crítica e outras avaliações".

- "Apresentação de trabalhos em seminários internos com a finalidade de receber críticas dos trabalhos em desenvolvimento".

- "Grupos onde são discutidas várias coisas relacionadas à informática, informatização, impacto organizacional em diversos setores, entre eles o agrícola. Essa discussão gira em torno da agricultura de precisão. Este grupo vai-se estruturando para montar uma rede de pesquisa que funcione a partir dos recursos da Internet 2. O objetivo seria o ganho e a colaboração dos participantes para o enriquecimento dos debates acerca do tema, com economia de recursos, já que muito ia ser feito via rede". 
. "Celebração de acordos de cooperação e parcerias com institutos regionais de pesquisa".

. "Colaboração na correção de versões em outros idiomas".

• "Como orientação de trabalhos de alunos de graduação e pós-graduação".

- "Elaboração de artigos em conjunto para participação em congresso e envio de informações sobre congressos e encontros nacionais".

. "Contato direto com profissionais de outras universidades".

. "Criação de referências pessoais e institucionais".

. "Desenvolvimento de trabalhos com colegas da instituição, em que os laços são mais estreitos, e criam facilidades para a superação de barreiras à pesquisa".

. "Discussão de temas, identificação e retificação de temas, problemas interdisciplinares".

. "Discussão informal com pesquisadores interessados em temas afins, tanto para a troca de material didático, como para a troca de idéias".

. "Divulgações de trabalhos".

. "Recebimento de chamadas de congressos nacionais e internacionais".

. "Intercâmbio de instrumentos de medida e de dados sobre as qualidades psicométricas deles".

- "Busca junto a pesquisadores argentinos e chilenos de pontes de contato na perspectiva de um trabalho conjunto sobre as realidades parecidas com que cada um trabalha em seu respectivo país".

. "Leitura de rascunho de trabalho de colegas, com vista ao oferecimento e recebimento de críticas e sugestões".

- "Procura por bibliografias. Procura também por publicações e por trabalho com contato direto com os autores".

. "Participação em bancas, troca de referências bibliográficas, co-orientação de trabalhos".

. "Pesquisa prioritária em journals e revistas específicas da área (RAE; RAUSP)".

- "Projetos conjuntos (parcerias) em elaboração de artigos, produtos de ensino e docência". 
. "Proximidade de afinidades teóricas ou de espaços próximos no trabalho".

- "Realização de seminários e reuniões, quando se cria a oportunidade de fato de colaboração e reciprocidade".

- "Contato com pesquisadores de destaque da área; busca de indicações de trabalhos e agendamento de palestras".

. "Pesquisa em banco de dados com orientandos".

Como se viu, o trabalho procurou apresentar dados sobre o uso de redes de relacionamento e cooperação entre os pesquisadores da área de administração. Os objetivos específicos foram relacionados como segue: identificar parâmetros atuais de uso de redes como instrumento facilitador e promotor de estudos e pesquisas; e contribuir com a avaliação de caminhos para a formação de grupos informais de pesquisadores. Relacionam-se agora as principais considerações finais possíveis de serem extraídas dos levantamentos efetuados, apesar das limitações impostas pela metodologia e outras restrições.

\section{Consideraçóes Finais}

A análise dos dados sobre o comportamento em rede dos pesquisadores torna claro que o modelo organizacional está mudando; estamos, de fato, no meio de uma revolução (Drucker, 1997). As mudanças na área de pesquisa aparentemente estão apenas começando. A tecnologia da informação direciona a estratégia que, por sua vez, modifica as estruturas e os hábitos enraizados das universidades e outras instituições de pesquisa de forma vagarosa, porém definitiva.

O problema não está mais em discutir se a tecnologia da informação traz benefícios ou não. Torna-se necessário investigar mais para se compreender o impacto dos novos modelos organizacionais e institucionais sobre a atuação dos pesquisadores, mais precisamente o reflexo desses modelos estruturados sobre a produção de pesquisas brasileiras em termos quantitativos e qualitativos. Observa-se claramente que os pesquisadores que forem capazes de utilizar as redes de pesquisa terão inúmeras oportunidades para melhorar o seu desempenho. Aqueles que não reagirem serão forçados a aceitar as mudanças, iniciadas por terceiros, para acabar apenas repetindo pesquisas, conforme constata Bastos (1999).

Este trabalho não consegue determinar com precisão as mudanças e suas extensões. Por meio de alguns indícios pode tirar algumas conclusões e prever 
alguns benefícios, auferidos com o uso de redes por pesquisadores, e algumas de suas influências mais significativas.

- Há pouca participação dos pesquisadores brasileiros da área de administração em redes de pesquisa existentes. Há indícios de que os principais fatores que restringem estão relacionados a questões culturais e comportamentais, mais do que a questões relacionadas à falta de tecnologia e recursos.

. A Internet já é um instrumento de uso comum no trabalho dos pesquisadores. Sua utilização se dá principalmente por meio de relacionamentos via correio eletrônico ou pesquisas simples no hipertexto, mas é empregada por poucos em relacionamentos e pesquisas mais aprofundadas e significativas, como as vinculadas aos institutos, journals, periódicos e às investigações compartilhadas.

. As redes onde atuam os pesquisadores brasileiros são, na sua grande maioria, pequenas e formadas principalmente por pesquisadores do país ou da própria instituição. Um dos aspectos identificados como significativos para a formação da rede é o profissionalismo dos participantes e as relações sociais e de amizade existentes. A perspectiva econômica ou financeira ainda não existe nas redes de pesquisa em que atuam os pesquisadores da amostra.

. Os participantes de redes geralmente percebem sua atuação como intensa, ou seja, participativa e colaborativa. A pequena atuação ocorre, quando os propósitos da rede não estão claramente definidos, ou há pouco conhecimento e, portanto, limitada confiança entre os participantes.

. O relacionamento em redes internacionais, ou com participação de pesquisadores de outros países tem sido importante instrumento de aprendizagem sobre comportamento, métodos e conteúdo de pesquisa.

- A participação nos grupos de pesquisa amplia as possibilidades de produção dos indivíduos, constatando-se o que a literatura relata sobre os motivos e resultados almejados para a participação: adquirir novos conhecimentos ou buscar maior envolvimento com a comunidade profissional para o alcance de maiores resultados nos projetos de investigação. Os resultados são ampliados por estarem cada vez mais ligados às relações com diferentes pesquisadores, em que a própria capacidade e a colaboração de outros participantes são complementares.

Observa-se, por meio dos dados levantados, que a rede, como instrumento de relacionamento e investigação, influencia positivamente as competências e o resultado quantitativo e qualitativo da produção. Esta efetividade, que corrobora as premissas da literatura, é extraída dos relacionamentos e da capacidade dos participantes em complementar suas competências com as habilidades dos ou- 
tros participantes; no entanto o modelo no Brasil ainda é emergente e pouco utilizado em todo o seu potencial. Assim, há dificuldades em se obterem dados suficientes para o estabelecimento das influências das relações existentes sobre os resultados organizacionais e institucionais como um todo.

Observam-se algumas iniciativas isoladas e bem sucedidas em termos de forma e conteúdo dos relacionamentos, cujo quadro corrobora a afirmação de Powell (1998), quando estabelece que essas capacidades não devem ser vistas como estáticas, mas emergentes e que se ampliam através do tempo, à medida que os participantes desenvolvem as relações existentes e exploram novas relações. Para esse fim, a formação de redes pode ser incentivada por estudos que identifiquem ainda mais os efeitos organizacionais de suas formas e conteúdos, à proporção que se desenvolvem e se enraízam; e, também, por meio do resultado do trabalho de alguns pesquisadores inovadores, que acreditam na força das relações e da confiança entre as pessoas, sejam estas profissionais ou sociais.

\section{ReferênCIAS BibLIOGRÁfICAS}

AMORIM, C. G.

Intensidade do relacionamento interorganizacional no setor turístico de Curitiba. Curitiba, 1999. Dissertação (Mestrado em Administração) - Centro de Pesquisa e Pós-Graduação em Administração, Universidade Federal do Paraná.

\section{CASTELLS, M.}

Prologue: the net and the self. In: The rise of network society. Oxford: Basil Blackwell, 1996.

CIRIA, F. B.

O uso comercial da Internet por micro, pequenas e médias empresas de Porto Alegre. In: XXI EN-
CONTRO ANUAL DA ANPAD (1997: Angra dos Reis). Anais Eletrônicos... Angra dos Reis: ANPAD, 1997.

DAFT, R.

Teoria e projeto organizacional. São Paulo: LTC, 1999.

DRUCKER, P. F.

$\mathrm{O}$ advir da nova organização. In: Revolução em tempo real. Rio de Janeiro: Campus, 1997.

FREEMAN, C.

Network of innovators: a synthesis of research issues. Research Policy, n. 20, p. 363379, 1991. 
JOHNSTON, R.;

LAWRENCE, P. R.

A era pós-integração vertical - $\mathrm{O}$ advento das parcerias de valor agregado. In: Revolução em tempo real. Rio de Janeiro: Campus, 1997.

NADLER, D.;

GERSTEIN, M.;

SHAW, R.

Arquitetura organizacional: a chave para a mudança empresarial. Rio de Janeiro: Campus, 1994.

\section{NOHRIA, N.}

Is a networking perspective a useful way of studying organizations? In: NOHRIA, N.; ECCLES, R. (Eds.). Networks and organizations: structure, forms and actions. Boston, MA: Harvard Business School Press, 1992.
POWELL, W. W.

Neither market nor hierarchy: network forms of organization. In: STAW, B.; CUMMINGS, C. (Eds.). Greenwich: Jay Press, 1995.

Learning from collaboration: knowledge and networks in the biotechnology and pharmaceutical industries. California Management Review, v. 40, n. 3, p. 228-240, Spring 1998.

RAMOS, A. S. M.

Análise fatorial da percepção do uso da Internet em organizações acadêmicas. In: XXII ENCONTRO ANUAL DA ANPAD (1998: Foz do Iguaçu). Anais Eletrônicos... Foz do Iguaçu: ANPAD, 1998.

SELLTIZ, J.;

DEUTSCH, C.

Métodos de pesquisa nas relações sociais. São Paulo: Editora Pedagógica e Universitária, 1974. 